
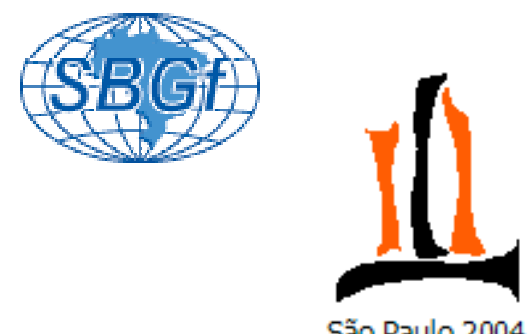

\title{
Conectividade e compartimentação estrutural-magnética dos sistemas aqüíferos Serra Geral e Guarani na região central do Arco de Ponta Grossa (Bacia do Paraná)
}

Carlos Vieira Portela Filho, Francisco José Fonseca Ferreira, Ernani Francisco da Rosa Filho, Sidnei Pires Rostirolla Departamento de Geologia/UFPR, Centro Politécnico, Jardim das Américas, Caixa Postal 19001, CEP 81531-980, CuritibaPR, e-mail:cal_geologia@hotmail.com, trancisco.ferreira@ufpr.br,ernani@ufpr.br,]sidnei@ufpr.br.

Copyright 2004, SBGf - Sociedade Brasileira de Geofísica

Este texto foi preparado para a apresentação no I Simpósio Regional da Sociedade Brasileira de Geofísica, São Paulo, 26-28 de setembro de 2004. Seu conteúdo foi revisado pela Comissão Tecno-científica do I SR-SBGf mas não necessariamente representa a opinião da SBGf ou de seus associados. E proibida a reprodução total ou parcial deste material para propósitos comerciais sem prévia autorização da SBGf.

\begin{abstract}
Research involving integration of aeromagnetic and hydrogeological data from the fractured Serra Geral Aquifer System (SGAS, basalts), was carried out to investigate the structural control of both flow and chemism of SGAS groundwater and to identify fractures that may be represent hydralic connection zones to the underlying granular Guarani Aquifer System (GAS). Qualitative interpretation of the aeromagnetic maps indicated a mosaic of tectonic blocks. The structuralmagnetic framework denoted that the largest dicrepances between the potentiometric surface and the relief are found at the Ponta Grossa Arch apex. In general, the SGAS typically shows average $\mathrm{pH}$ of 7.3 and total dissolved solids between $80-120 \mathrm{mg} / \mathrm{L}$, and values respectively above 8.0 and $150 \mathrm{mg} / \mathrm{L}$ where contamined by GAS waters. The spatialization of anions and cations in ternary RBG maps (modified Piper diagrams), indicated that the typical SGAS waters are bicarbonated calcic, followed bicarbonated calcic-sodic and calcicmagnesian. In areas with contributed GAS waters, bicarbonated sodic and, secondarily, bicarbonated sodiccalcic are present.
\end{abstract}

\section{Introdução}

O reconhecimento aeromagnetométrico de grandes zonas de falhas de direção geral NW-SE, no sul-sudeste do Brasil, preenchidas por cerrados enxames de diques de doleritos, permitiu a proposição de uma nova configuração para o Arco de Ponta Grossa (APG), constituída por quatro alinhamentos estruturais: Guapiara (limite setentrional), São Jerônimo-Curiúva e Rio Alonso (região central) e Rio Piquiri (limite meridional). Os alinhamentos exibem extensões mínimas de $600 \mathrm{~km}$, larguras máximas de $100 \mathrm{~km}$ na região central do arco, e distribuem-se desde a margem continental contígua até pelo menos o rio Paraná. Tais estruturas de direção geral NW-SE, em conjunção com outras dispostas segundo NE-SW, E-W e N-S, contribuíram para o estabelecimento de um novo arcabouço estrutural da Bacia do Paraná. A proposição recente de projetos de pesquisa hidrogeológica na Bacia do Paraná, cujo foco central é avaliar o potencial, o fluxo, o quimismo e a proteção ambiental das águas subterrâneas do Sistema Aqüífero Guarani (SAG), em correspondência ao arcabouço estrutural, motivou investigar a partir de uma área fortemente estruturada da região central do APG, limitada pelas coordenadas geodésicas $23^{\circ} 00^{\prime}-24^{\circ} 00^{\prime}$ de latitude sul e $51^{\circ} 00^{\prime}-52^{\circ} 00^{\prime}$ de longitude oeste (Figura 1), as eventuais relações entre dados geofísicos, geológicos e hidrogeológicos. Na região norte do Paraná, o abastecimento de água a partir do Sistema Aqüífero Serra Geral (SASG) é essencial para suprir o aumento do consumo decorrente do crescimento populacional dos grandes centros urbanos. Este sistema aqüífero fissural apresenta condições hidrogeológicas heterogêneas e anisotrópicas, o qual oferece água de boa qualidade para o consumo humano. Os poços completados no SASG apresentam vazões maiores quando situados próximos a lineamentos estruturais. Em condições especiais pode ocorrer a conexão do SASG fissural com o SAG granular, sotoposto, modificando as características químicas das águas nos basaltos. Águas de poços perfurados no SASG que apresentam influência do sistema aqüífero subjacente são normalmente alcalinas e exibem teores de sódio mais elevados que os de cálcio. Acredita-se que a conexão dos aqüíferos esteja relacionada com a presença de estruturas profundas, por onde as águas do SAG podem ascender, através de condições potenciométricas favoráveis, e se mesclarem com águas do sistema aqüífero sobrejacente.

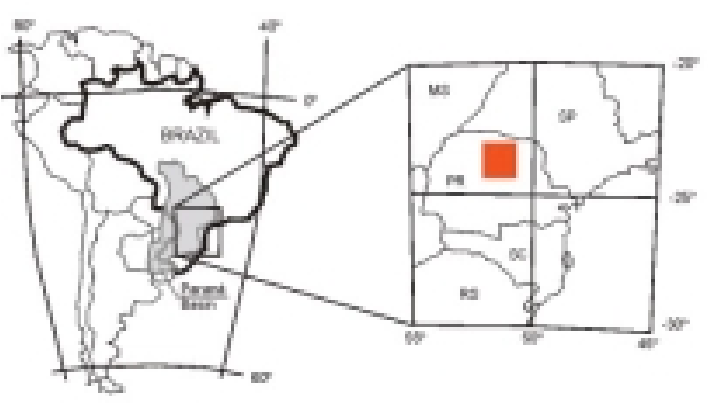

Figura 1 - Mapa de localização da área de estudo. 
Conectividade e Compartimentação dos Sistemas AqüífERos SerRa GeRAL E GuARANı

\section{Métodos}

Através da análise de dados aeromagnéticos, procurouse caracterizar as estruturas da área do estudo e avaliar suas relações com a circulação de águas subterrâneas do Sistema Aqüífero Serra Geral (SASG, fissural) e identificar possíveis áreas de conexão hidráulica com o Sistema Aqüífero Guarani (SAG, granular), sotoposto. Neste trabalho, os dados magnéticos foram processados e interpretados principalmente pelos métodos do sinal analítico (amplitude e fase) e do gradiente horizontal total (Figuras 2, 3 e 4). Também foi utilizada a técnica da deconvolução de Euler, a qual possibilitou estimar a profundidade das fontes anômalas e definir novos lineamentos estruturais (Portela Filho 2003). Com a finalidade de complementar a interpretação estruturalmagnética, foi realizado um estudo de resolução dos dados magnéticos na identificação de diques, através da análise de perfis terrestres e da correlação com a geologia de uma área contígua, onde as estruturas de interesse foram mapeadas por fotointerpretação e trabalhos de campo, apresentando boa correspondência com a interpretação aeromagnética, para o propósito de integração geofísico-geológica (Portela Filho 2003). A partir das informações geradas pelos dados aeromagnéticos, objetivou-se avaliar as possíveis influências das estruturas na circulação das águas do SASG. Os dados hidrogeológicos cedidos pela Superintendência de Desenvolvimento de Recursos Hídricos e Saneamento Ambiental (Suderhsa), estado do Paraná, foram processados a partir de 625 poços completados na Formação Serra Geral, situados na área do estudo, onde foram contemplados parâmetros como potenciometria, vazão, capacidade específica, $\mathrm{pH}$ e sólidos totais dissolvidos. Para identificar zonas de conexão hidráulica entre o SASG e o SAG, foram considerados dados hidroquímicos dos cátions $\left(\mathrm{Na}^{+}+\mathrm{K}^{+}\right.$; $\left.\mathrm{Ca}^{++} ; \mathrm{Mg}^{++}\right)$e dos ânions $\left(\mathrm{Cl}^{-} ; \mathrm{HCO}_{3}{ }^{-}+\mathrm{CO}_{3}{ }^{--} ; \mathrm{SO}_{4}^{--}\right)$de 57 poços que apresentaram diferenças de balanço iônico menores que 10\% (Portela Filho 2003), uma vez que, através de condições potenciométricas favoráveis do SAG, as águas ascendem até a Formação Serra Geral por meio de estruturas geológicas. Finalmente, a espacialização dos parâmetros hidrogeológicos e hidroquímicos foi cotejada com o arcabouço magnético interpretado, no sentido de determinar a influência das estruturas na dinâmica do fluxo e no quimismo das águas dos mencionados sistemas aqüíferos.

\section{Resultados e Discussões}

O mapa da superfície potenciométrica (Figura 5), mostra uma forte tendência de sudeste para noroeste, com as cotas mais elevadas ( \pm 850 metros) situadas no quadrante $\mathrm{SE}$, as quais decaem gradativamente até atingirem valores da ordem de \pm 400 metros no extremo NW, portanto mergulhando para o interior da bacia. Esta configuração coincide com o eixo do APG, a qual está em conformidade com a topografia (Figura 6 ), denotando um comportamento de aqüífero livre. A partir deste alto central, a superfície potenciométrica decresce gradativamente também nos sentidos NE e SW, atingindo as menores cotas em seus respectivos extremos $( \pm 350 m)$.

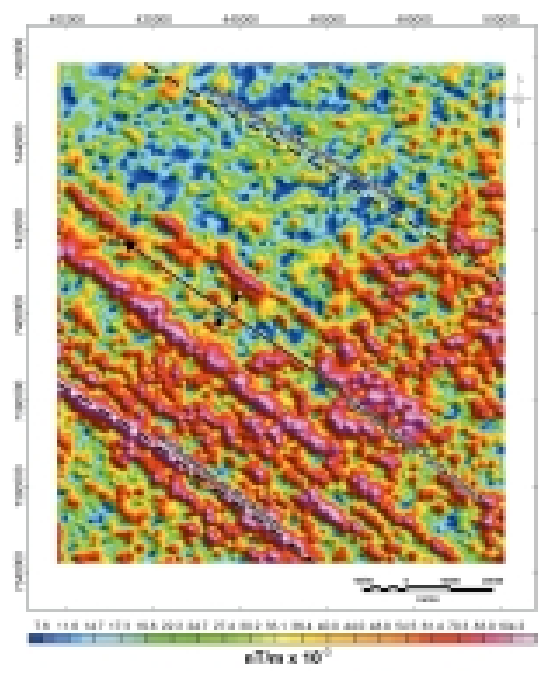

Figura 2 - Amplitude do sinal analítico.

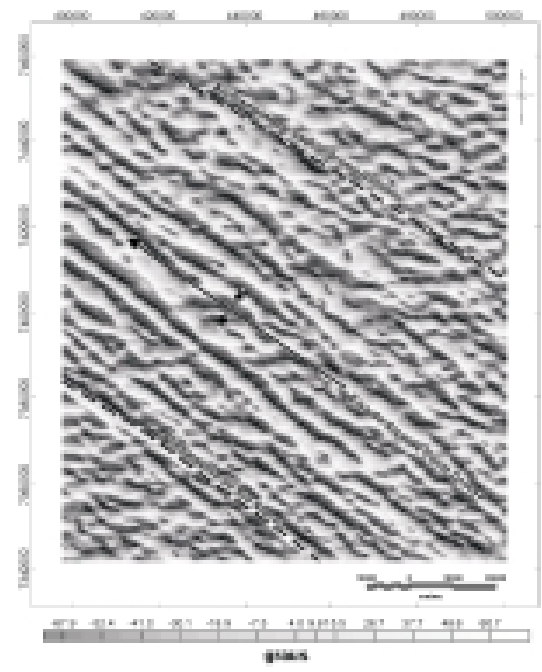

Figura 3 - Fase do sinal analítico.

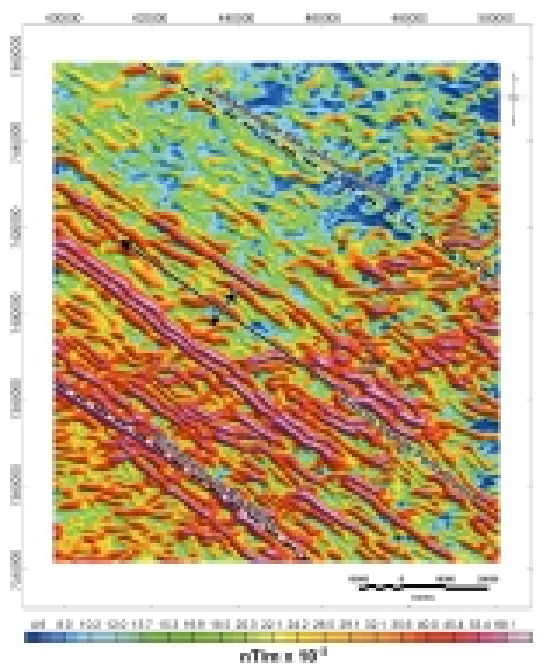

Figura 4 - Gradiente horizontal total. 
Carlos V. Portela Filho, Francisco J. F. Ferreira, Ernani F. da Rosa Filho, Sidnei Pires Rostirolla

Um perfil de direção SW-NE (Figura 7), permitiu relacionar a superfície potenciométrica e a topografia da área (Figura 5). Nota-se que a superfície potenciométrica normalmente apresenta variações locais, as quais não seguem a tendência geral da topografia da área. As maiores discrepâncias entre estas superfícies são verificadas na porção central da área, coincidentes com o ápice do APG, portanto denotando controle estrutural. Outra característica relacionada ao comportamento local do SASG é a elevação da superfície potenciométrica, que se torna surgente (fontes) nas terminações SW e NE do perfil, próximas às duas principais drenagens da região, rios Ivaí e Tibagi, respectivamente. Nos mapas de vazão (Figura 8) e de capacidade específica (Figura 9), observa-se uma compartimentação regional balizada pelo eixo do APG, onde a nordeste desta estrutura ocorre vazões e capacidades específicas elevadas, em contraste com a porção sudoeste.

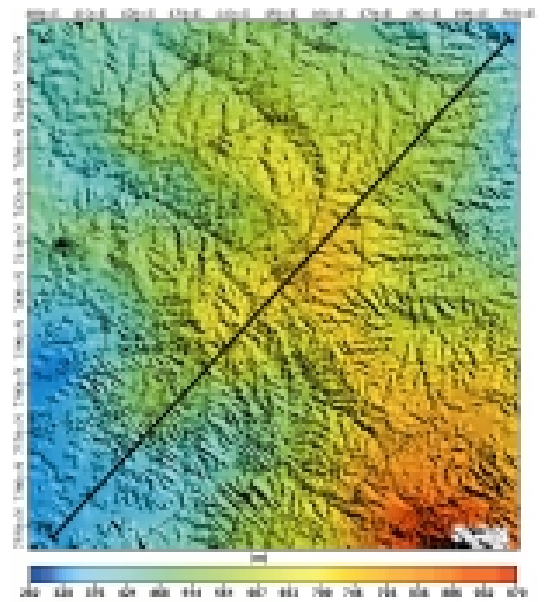

Figura 5 - Potenciometria sobreposta ao relevo.

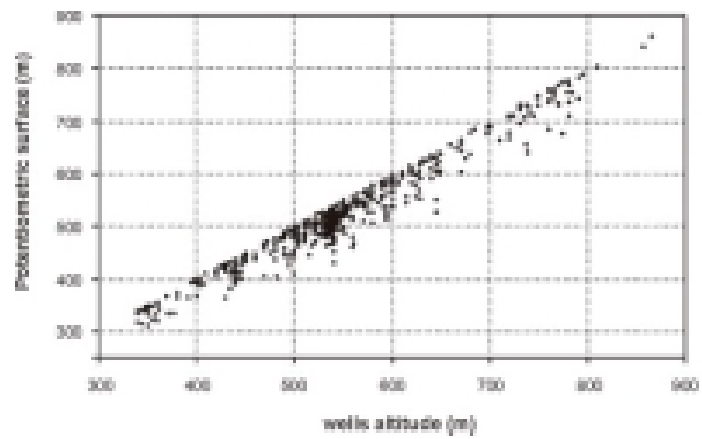

Figura 6 - Correlação entre potenciometria e relevo.

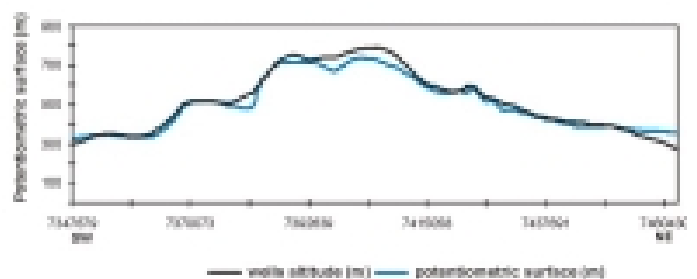

Figura 7 - Correlação entre entre perfis potenciométrico e altimétrico, indicando as discrepâncias no ápice do APG e as surgências nas extremidades (derivado da Figura 5).
Entretanto, em escala de maior detalhe, nota-se que as áreas com alta produtividade estão confinadas em compartimentos romboédricos balizados por estruturas direcionadas segundo as direções NW-SE e NE-SW. A moldura estrutural-magnética sobreposta a estes mapas, mostra também que os tratos de maior produtividade estão respectivamente controlados pelo Alinhamento São Jerônimo-Curiúva, sobretudo os núcleos a norte de Londrina, onde existem mais dados, e pelos alinhamentos de Arapongas e Apucarana, definidos por Portela Filho (2003), próximos ao eixo do arco, onde a densidade de diques de dolerito é maior. Na porção central da área, a ocorrência de valores anômalos de capacidade específica (Figura 9) é constatada justamente sobre alinhamentos de direção NW-SE (eixo do APG).

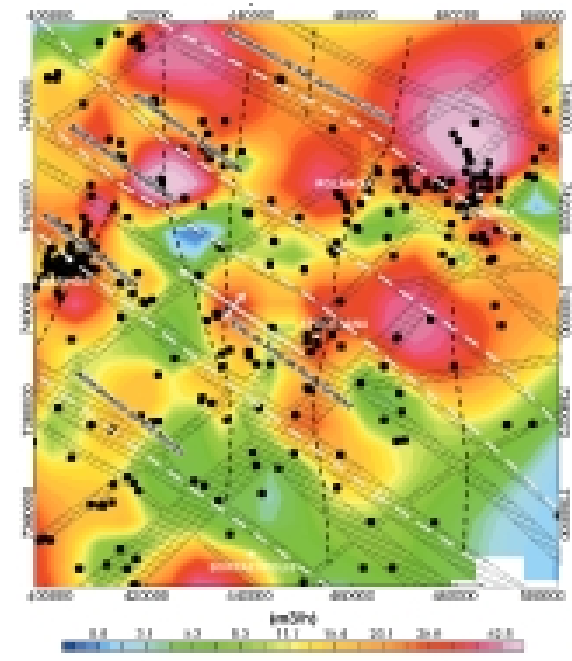

Figura 8 - Mapa de vazão.

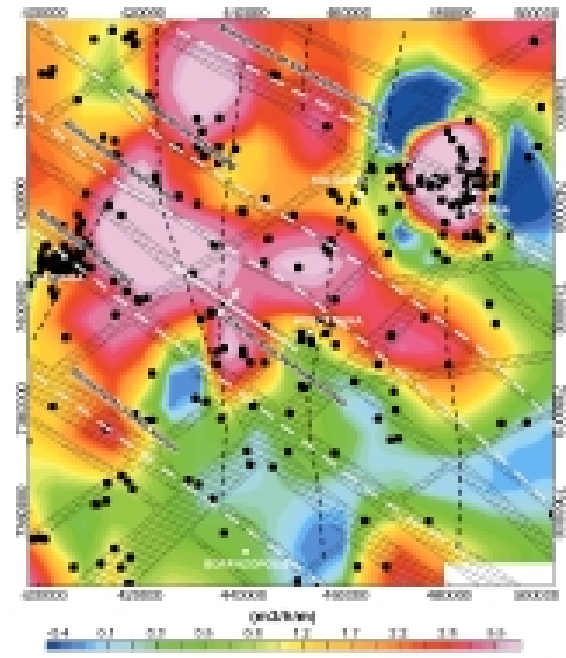

Figura 9 - Mapa de capacidade específica.

O mapa de contorno dos sólidos totais dissolvidos (STD, Figura 10), exibe claramente três áreas de maior concentração, respectivamente a nordeste do Alinhamento São Jerônimo-Curiúva, no extremo noroeste da região entre os alinhamentos de Maringá e Apucarana, também definidos por Portela Filho (2003), e 
Conectividade e Compartimentação dos Sistemas AqüífERos SerRa Geral e GuARANı

à sudoeste do Alinhamento do Rio Alonso, denotando a influência das estruturas do APG na distribuição dos teores. Altos valores de STD denotam águas com maior tempo de residência no aqüífero, indicando que podem estar entremeadas com águas provenientes de outros reservatórios sotopostos. A análise conjunta dos três últimos mapas revela que as áreas com elevadas vazões e capacidades específicas coincidem com aquelas de menores teores de STD. O mapa do potencial hidrogeniônico (Figura 11) foi gerado a partir dos dados de 507 poços, onde se pode observar que os valores alcalinos, em vermelho, apresentam tendências segundo as principais direções estruturais, e que as maiores concentrações normalmente estão nos cruzamentos destas. As águas típicas do SASG têm pH em torno da neutralidade, enquanto $\mathrm{pH}$ alcalinos são atribuídos a contaminação pelas águas do SAG, o que pode constituir um guia na ausência de um número expressivo de análises hidroquímicas devidamente balanceadas iônicamente. Finalmente os mapas ternários da Figura 12 mostram a compartimentação das águas típicas do SASG, as quais são predomiantemente bicarbonatas cálcicas, mas também bicarbonatadas cálcio sódicas a cálcio magnesianas. Já as águas bicarbonatadas sódicas e bicarbonatadas sódio cálcias são características de conexão com o SAG, as quais também denotam controle estrutural.

\section{Conclusões}

Os métodos utilizados e os resultados obtidos, em termos de conectividade e compartimentação dos SASG e SAG, poderão ser úteis para sua exploração/explotação sustentável e proteção ambiental.

\section{Referência}

Portela Filho, C. V. 2003. Condicionamento estruturalmagnético do Sistema Aqüífero Serra Geral na região central do Arco de Ponta Grossa e sua conectividade com o Sistema Aqüífero Guarani. Dissertação de Mestrado, Departamento de Geologia/UFPR, 128p.

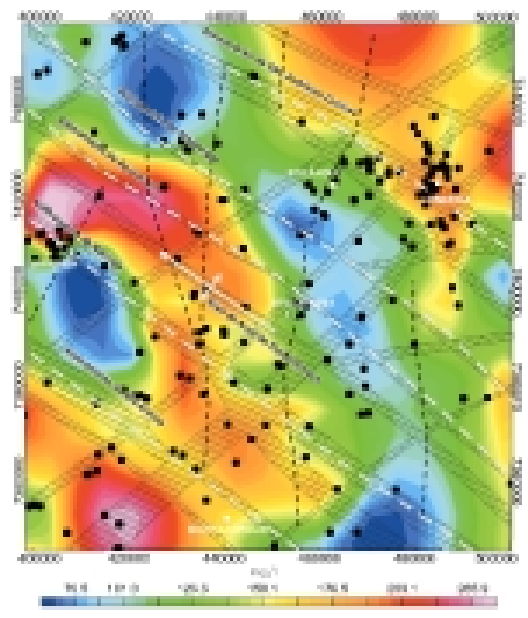

Figura 10 - Mapa dos sólidos totais dissolvidos (STD).

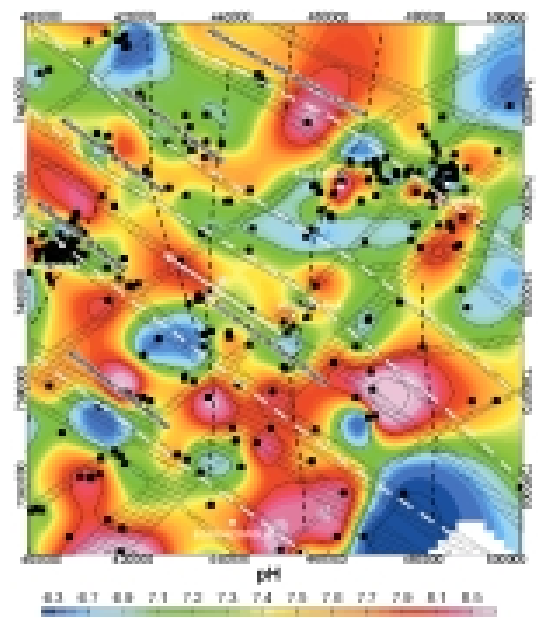

Figura 11 - Mapa do potencial hidrogeniônico $(\mathrm{pH})$.
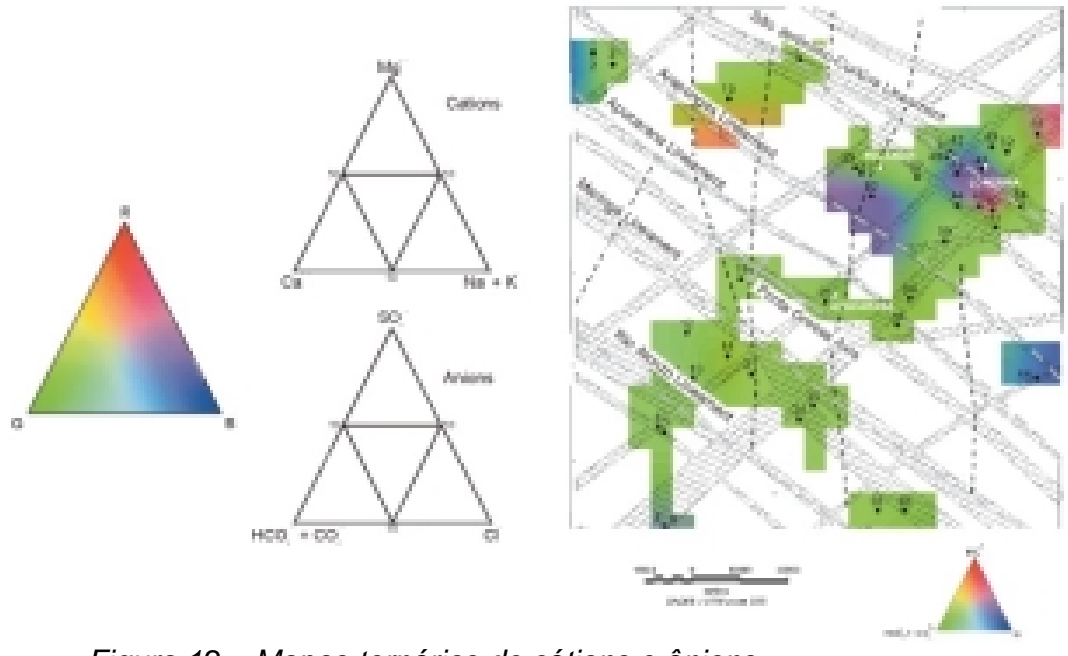

Figura 12 - Mapas ternários de cátions e ânions.

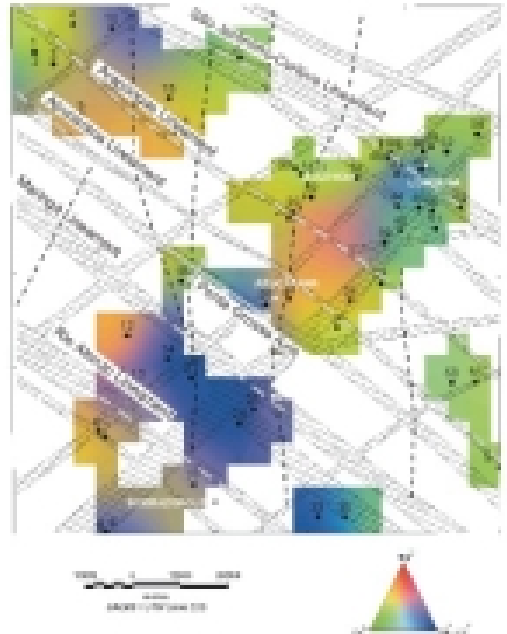

